\title{
Integration of Asynchronously Released Quanta Prolongs the Postsynaptic Spike Window
}

\author{
Karl J. Iremonger and Jaideep S. Bains \\ Hotchkiss Brain Institute and Department of Physiology and Biophysics, University of Calgary, Calgary, Alberta, Canada T2N 4N1
}

Classically, the release of glutamate in response to a presynaptic action potential causes a brief increase in postsynaptic excitability. Previous reports indicate that at some central synapses, a single action potential can elicit multiple, asynchronous release events. This raises the possibility that the temporal dynamics of neurotransmitter release may determine the duration of altered postsynaptic excitability. In response to physiological challenges, the magnocellular neurosecretory cells (MNCs) in the paraventricular nucleus of the hypothalamus (PVN) exhibit robust and prolonged increases in neuronal activity. Although the postsynaptic conductances that may facilitate this form of activity have been investigated thoroughly, the role of presynaptic release has been largely overlooked. Because the specific patterns of activity generated by MNCs require the activation of excitatory synaptic inputs, we sought to characterize the release dynamics at these synapses and determine whether they contribute to prolonged excitability in these cells. We obtained whole-cell recordings from MNCs in brain slices of postnatal day 21-44 rats. Stimulation of glutamatergic inputs elicited large and prolonged postsynaptic events that resulted from the summation of multiple, asynchronously released quanta. Asynchronous release was selectively inhibited by the slow calcium buffer EGTA-AM and potentiated by brief high-frequency stimulus trains. These trains caused a prolonged increase in postsynaptic spike activity that could also be eliminated by EGTA-AM. Our results demonstrate that glutamatergic terminals in PVN exhibit asynchronous release, which is important in generating large postsynaptic depolarizations and prolonged spiking in response to brief, high-frequency bursts of presynaptic activity.

Key words: asynchronous release; glutamate; paraventricular; synaptic transmission; spiking; prolonged depolarization

\section{Introduction}

At the majority of nerve terminals in the vertebrate CNS, the probabilistic release of neurotransmitter occurs in a relatively rapid manner after a single action potential. This ensures the precise and temporally coordinated relay of information from presynaptic to postsynaptic neuron. There are, however, clear demonstrations that in addition to this rapid (synchronous) release, select nerve terminals can also exhibit a delayed (asynchronous) form of transmitter release during which additional quanta fuse for up to hundreds of milliseconds after a presynaptic depolarization (Rahamimoff and Yaari, 1973; Cohen and Van der Kloot, 1986; Atluri and Regehr, 1998; Lu and Trussell, 2000; Otsu et al., 2004; Hefft and Jonas, 2005; Hjelmstad, 2005). Whereas the cost of delayed release is clear (a breakdown of the temporal fidelity that exists between the presynaptic and postsynaptic cell) the benefit of such a signaling process has not been addressed clearly.

Stimulation in vivo of afferent inputs to magnocellular neuro-

Received March 1, 2007; revised May 14, 2007; accepted May 14, 2007.

This work was supported by an operating grant from the Canadian Institutes for Health Research. K.J.I. was supported by a studentship from the Alberta Heritage Foundation for Medical Research (AHFMR). J.S.B. is an AHFMR Senior Scholar. We are deeply indebted to Dr. Y. Ueta for generously providing access to the eGFP-VP transgenic rats. We also thank Cheryl Sank for technical assistance and the Bains laboratory for helpful discussions.

Correspondence should be addressed to Jaideep S. Bains, Hotchkiss Brain Institute and Department of Physiology and Biophysics, University of Calgary, 3330 Hospital Drive, NW, Calgary, Alberta, Canada T2N 4N1. E-mail: jsbains@ucalgary.ca.

DOI:10.1523/JNEUROSCI.0934-07.2007

Copyright $\odot 2007$ Society for Neuroscience $\quad$ 0270-6474/07/276684-08\$15.00/0 secretory cells (MNCs) in the paraventricular nucleus of the hypothalamus $(\mathrm{PVN})$ results in an increase in postsynaptic spike probability that can last for over a hundred milliseconds (Ferguson et al., 1984; Li and Ferguson, 1993). Although this may be accomplished through the release of neuropeptides (Li and Ferguson, 1993; Wang and Hatton, 2007) or the recruitment of active conductances, which prolong the duration of the depolarization after an EPSP or postsynaptic spike (Bourque et al., 1985; Bourque and Renaud, 1991; Armstrong et al., 1994; Fisher et al., 1998; Roper et al., 2004), the specific activity patterns observed in vivo during physiological recruitment cannot be replicated in the absence of synaptic input (Nissen et al., 1995; Brown et al., 2004). This suggests that afferent inputs, and in particular, the dynamics of release at the terminals, may be critically important in generating these unique spike patterns.

Currently, there is little information about the dynamics of glutamate release on MNCs. Observations of multiple, temporally dispersed synaptic events in response to a single stimulus have been reported (Boudaba et al., 1997), but it is not known whether these result from the activation of polysynaptic circuits, or whether they reflect the asynchronous release of glutamate. Here, using an acute hypothalamic slice preparation, we describe and examine the properties of asynchronous release at glutamatergic synapses on MNCs. Our findings reveal that a single, presynaptic action potential elicits a barrage of postsynaptic, AMPAmediated events that can persist for up to $100 \mathrm{~ms}$. The flurry of events is not caused by activation of polysynaptic circuits, but 
results from asynchronous glutamate release. This release relies on residual presynaptic calcium and can be potentiated during short, physiologically relevant (Washburn et al., 2000) trains of stimuli. Furthermore, we explore the contributions of asynchronous release to prolonged excitation in MNCs. Our results indicate that these additional quanta are ideally suited to increase the probability of spike generation in the postsynaptic neuron over a broad time window. Portions of this study have been published previously in abstract form (Iremonger and Bains, 2006).

\section{Materials and Methods}

All experiments were performed according to protocols approved by the University of Calgary Animal Care and Use Committee in accordance with guidelines established by the Canadian Council on Animal Care. Slice preparation. Male Sprague Dawley rats [postnatal day 21 (P21)$\mathrm{P} 44$ ] were anesthetized with sodium pentobarbital $(0.1 \mathrm{ml} / 100 \mathrm{~g}$ of body weight) and then decapitated. In a subset of experiments, transgenic Wistar/Sprague Dawley rats that express enhanced green fluorescence protein (eGFP) driven by the vasopressin promoter were used (Ueta et al., 2005). The brain was then quickly removed and placed in ice-cold slicing solution containing (in $\mathrm{mm}$ ) $87 \mathrm{NaCl}, 2.5 \mathrm{KCl}, 25 \mathrm{NaHCO}_{3}, 0.5$ $\mathrm{CaCl}_{2}, 7 \mathrm{MgCl}_{2}, 1.25 \mathrm{NaH}_{2} \mathrm{PO}_{4}, 25$ glucose, and 75 sucrose, saturated with $95 \% \mathrm{O}_{2} / 5 \% \mathrm{CO}_{2}$, for several minutes. The brain was then blocked and mounted on a vibrating slicer (Leica, Nussloch, Germany) submerged in ice-cold slicing solution. Slices were incubated at $32.5^{\circ} \mathrm{C}$ in artificial CSF (ACSF) containing (in $\mathrm{mm}$ ) $126 \mathrm{NaCl}, 2.5 \mathrm{KCl}, 26$ $\mathrm{NaHCO}_{3}, 2.5 \mathrm{CaCl}_{2}, 1.5 \mathrm{MgCl}_{2}, 1.25 \mathrm{NaH}_{2} \mathrm{PO}_{4}$, and 10 glucose, saturated with $95 \% \mathrm{O}_{2} / 5 \% \mathrm{CO}_{2}$, for a minimum of $60 \mathrm{~min}$.

Electrophysiology. Slices containing the PVN were submerged in a recording chamber and superfused with $32.5^{\circ} \mathrm{C}$ artificial CSF at a flow rate of $1 \mathrm{ml} / \mathrm{min}$. Whole-cell recordings were obtained from MNCs visualized either with an AxioskopII FS Plus (Zeiss, Oberkochen, Germany) or BX51WI (Olympus Optical, Tokyo, Japan) upright microscope fitted with infrared differential interference contrast optics. Recorded cells were confirmed to be MNCs based on their morphology and well defined electrophysiological characteristics (Luther and Tasker, 2000). eGFP neurons were visualized with a Zeiss AxioCam MRm with excitation at $488 \mathrm{~nm}$ and emission at $509 \mathrm{~nm}$.

Patch pipettes were pulled from borosilicate glass, had a resistance between 3 and $7 \mathrm{M} \Omega$ and were filled with a solution containing (in $\mathrm{mm}$ ) 123 potassium gluconate, $2 \mathrm{MgCl}_{2}, 8 \mathrm{NaCl}, 1$ potassium EGTA, 4 potassium ATP, and 0.3 sodium GTP buffered with $16 \mathrm{~mm} \mathrm{KHCO}_{3}$. Recordings were accepted for analysis if changes in access resistance were $<15 \%$. During all voltage-clamp recordings, cells were held at $-60 \mathrm{mV}$. The liquid junction potential was calculated to be approximately $-13 \mathrm{mV}$ and was not compensated.

The perfusate always contained picrotoxin (100 $\mu \mathrm{M}$; Sigma-Aldrich, St. Louis, $\mathrm{MO}$ ) to block $\mathrm{GABA}_{\mathrm{A}}$-mediated conductances. Glutamatergic fibers were stimulated extracellularly with a patch pipette filled with ACSF placed either within or just outside of the PVN.

Data collection and analysis. Signals were amplified with the Multiclamp 700B amplifier (Molecular Devices, Union City, CA) were lowpass filtered at $1 \mathrm{kHz}$ (for voltage clamp), digitized at $10-20 \mathrm{kHz}$ with the Digidata 1322 (Molecular Devices) and saved on a personal computer for off-line analysis. Analysis was performed using either pClamp 10 (Molecular Devices) or Minianalysis (Synaptosoft, Decatur, GA) software. Charge transfer from single EPSCs was calculated by integrating the area under the average of 30 EPSCs from 0 to $10 \mathrm{~ms}$ for the synchronous component and 10-100 ms for the asynchronous component. The number of individual delayed release events was quantified by counting the occurrence of mEPSCs from 5 to $100 \mathrm{~ms}$ after the onset of the EPSC ( $5 \mathrm{~ms}$ bins) during 30 trials. Events were not counted in the first $5 \mathrm{~ms}$ because they could not be discriminated from the synchronous component. During the 5-10 ms time window (decay of the synchronous EPSC), we could clearly discern individual quanta and these were counted as asynchronous events. Baseline spontaneous release was calculated for the $100 \mathrm{~ms}$ before the stimulus and subtracted.

In the voltage-clamp train experiments, the synchronous component of release (pC) was calculated in $20 \mathrm{~ms}$ bins from the onset of the synchronous EPSC. Baseline was taken as the current immediately before the stimulus artifact of each pulse. The asynchronous component was calculated by finding the total charge transfer from the onset of the first stimuli to $1000 \mathrm{~ms}$ (with stimulus artifacts blanked), then subtracting the synchronous component.

For the current-clamp spiking experiments, action potentials were detected using a threshold search in pClamp. Spikes evoked by synchronous release were counted in the $20 \mathrm{~ms}$ after each stimulus artifact, whereas asynchronous spikes following the train were counted in the $20-520 \mathrm{~ms}$ after the last stimuli of the train. The number of spikes reported represents the total from 30 trials in an experiment. Average baseline spiking activity was recorded before each stimulus train and subtracted.

All data are presented as mean \pm SEM and statistical analyses were performed with Student's $t$ test when comparing two groups and with ANOVA with a post hoc Newman-Keuls test for comparisons across multiple groups. A value of $p<0.05$ was accepted as statistically significant.

\section{Results}

\section{Prolonged EPSPs in MNCs result from asynchronous glutamate release}

Single evoked EPSPs recorded from MNCs produced large, prolonged depolarizations with a mean peak amplitude of $8.4 \pm 0.9$ $\mathrm{mV}$ (range, $2.6-18.9 \mathrm{mV} ; n=26$ ). In contrast, spontaneous EPSPs (sEPSPs) had a mean amplitude of $2.1 \pm 0.2 \mathrm{mV}$ (range, $0.4-9.2 \mathrm{mV} ; n=9$ ) (Fig. $1 A$ ). The decay time constant of evoked EPSPs was slower than that of spontaneous quantal EPSPs $(34.9 \pm 6.2$ and $17.5 \pm 3.1 \mathrm{~ms}$, respectively; $n=7 ; p<0.05)$.

In voltage clamp, evoked EPSCs $(0.2 \mathrm{~Hz})$ showed two components of release: an initial, fast component (synchronous release) that was followed by a barrage of quantal events. This second component, which is less common and is characterized by a prolonged increase in release probability has previously been termed asynchronous release (Fig. 1 B) (Barrett and Stevens, 1972; Rahamimoff and Yaari, 1973; Cohen and Van der Kloot, 1986; Atluri and Regehr, 1998). The frequency decay of the asynchronous release events was fit with a single exponential with a $\tau$ of $10.9 \mathrm{~ms}$ $(n=23)$ (Fig. 1C). Analysis of fractional charge transfer revealed that the asynchronous component of release accounted for $0.50 \pm 0.03$ of total release $(n=29)$. Both the synchronous and asynchronous components of release were equally inhibited by high concentrations of DNQX (10 $\mu \mathrm{M} ; n=4)$ (data not shown).

Previous reports in PVN suggest that the delayed release observed after synaptic stimulation may result from the activation of polysynaptic circuits (Boudaba et al., 1997). To test this idea directly, we partially antagonized fast glutamatergic transmission with a low concentration of DNQX $(500 \mathrm{nM})$. We reasoned that if synchronous release was caused by monosynaptic transmission and asynchronous release relied on polysynaptic activation, low doses of DNQX should preferentially inhibit the delayed asynchronous component. At this concentration, DNQX reduced the EPSC peak amplitude from $-112.9 \pm 32.8 \mathrm{pA}$ to $-46.3 \pm 5.7 \mathrm{pA}$ $(n=6 ; p<0.05)$. Asynchronous release, however, was not inhibited preferentially. Instead, low concentrations of DNQX shifted the fraction of asynchronous release (asynchronous charge/total charge) from $0.45 \pm 0.04$ to $0.51 \pm 0.03(n=6 ; p<$ 0.05) (data not shown).

To determine whether synchronous and asynchronous release result from the activation of the same fibers, we conducted experiments to test for the threshold for activation of each component. In 10 of 13 cells tested, synchronous and asynchronous components of release exhibited identical thresholds for activation (Fig. $2 A)$. This is consistent with the idea that both components of 
A

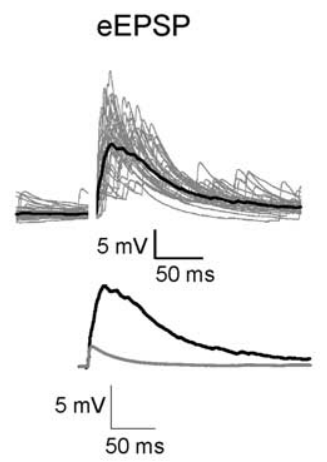

B

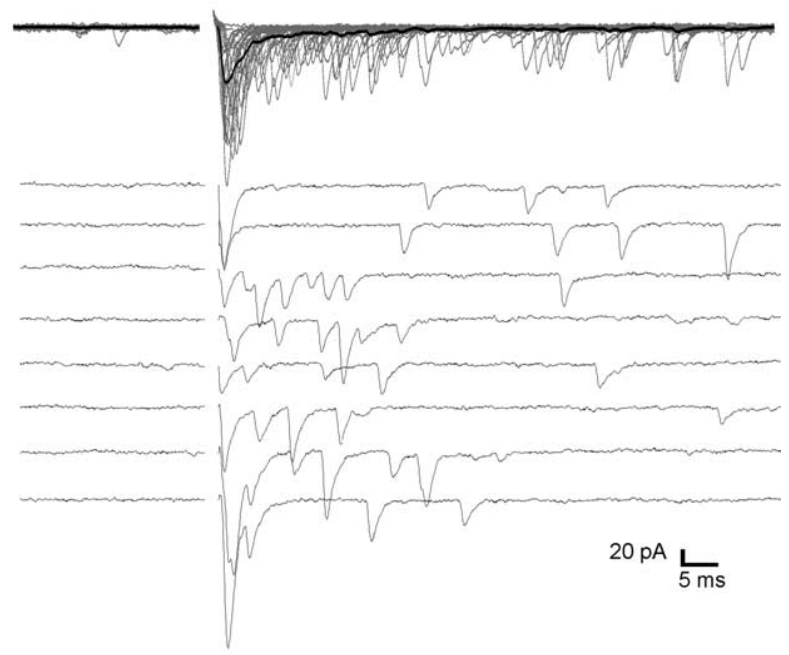

\section{C}

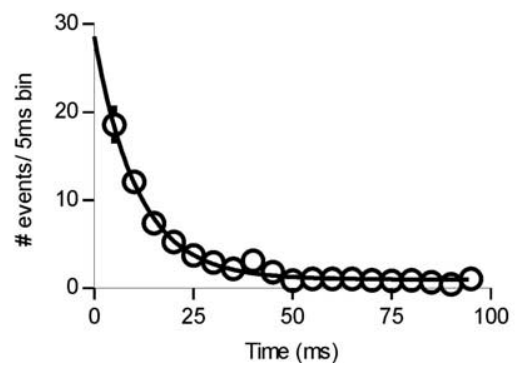

Figure 1. Characterization of asynchronous glutamate release onto MNCS. A, Top, Evoked EPSPs (eEPSPs) exhibit a prolonged decay compared with sEPSP. Individual events are shown in gray (30 eEPSPs; 147 sEPSPs) and average events in black. Bottom left, Overlaid average traces of eEPSPs (black) and sEPSPs (gray). Bottom right, Peak scaled average spontaneous (gray) and evoked (black) EPSPs. $\boldsymbol{B}$, In voltage-clamp mode, synaptic stimulation elicits EPSCs that are asynchronous. Top, Thirty trials at $0.2 \mathrm{~Hz}$ overlaid; bottom, same cell, 10 traces distributed. Stimulus artifacts have been removed for clarity. $C$, The number of asynchronous events after single stimuli decay exponentially with a time constant of $10.9 \mathrm{~ms}(n=23)$.

release can occur from the activation of the same fiber and argue against the hypothesis that delayed release results from the recruitment of polysynaptic circuits.

There is some evidence for a developmental speeding of EPSPs that may be attributable to multiple mechanisms (Cathala et al., 2003), including reduced asynchronous release (Fedchyshyn and Wang, 2005). To ensure that the asynchronous release we observed was not limited to younger animals $(<\mathrm{P} 30)$, we obtained recordings from $\mathrm{P} 43-\mathrm{P} 44$ animals. These animals displayed similar asynchronous release to younger animals and the relationship of synchronous to asynchronous was also similar (Fig. $2 B, C$ ).

Collectively, these findings indicate that glutamatergic affer-

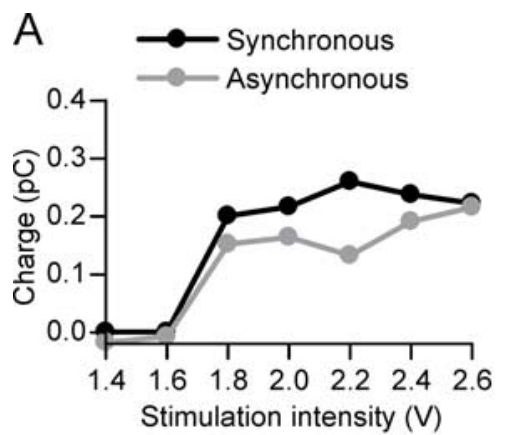

B
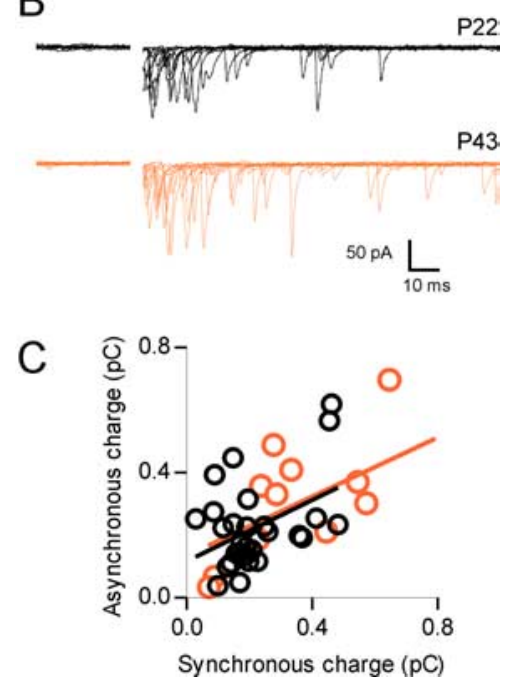

Figure 2. Asynchronous release is not polysynaptic or age dependent. $A$, Data from a single cell demonstrates that both the synchronous and asynchronous components of release have a similar threshold for activation. $\boldsymbol{B}$, Representative traces obtained from a young (P22, black traces) and older (P43, orange traces) rat show that asynchronous release is evident at both ages. C, Correlation of charge transfer for the synchronous component versus the asynchronous component for different cells obtained from both young (P21-P28; $n=29 ;$ black) and older (P43-P44; $n=12$; orange) animals. The $R^{2}$ values for the linear regression in $C$ are 0.18 and 0.35 for the young and older animals, respectively.

ents in the PVN are capable of releasing in a combined synchronous and asynchronous manner and that the summation of these events in the postsynaptic cell can generate prolonged, robust membrane depolarizations.

\section{Asynchronous release is not dependent on postsynaptic cell phenotype}

Oxytocin (OT) MNCs can release OT (Moos et al., 1989; Brussaard et al., 1996; Kombian et al., 1997; Ludwig et al., 2002; Sabatier et al., 2003) and endocannabinoids (Hirasawa et al., 2004; Oliet et al., 2007) from their dendrites. Likewise, vasopressin (VP) cells can release VP (Pow and Morris, 1989) or dynorphin (Watson et al., 1982). These molecules have all been shown previously to modulate neurotransmission in the $\mathrm{PVN}$ or supraoptic nucleus (Brussaard et al., 1996; Kombian et al., 1997; Hirasawa et al., 2003; Oliet et al., 2007). Although the vast majority of EPSCs recorded in MNCs displayed synchronous followed by asynchronous release, we did record EPSCs in some cells that displayed robust asynchronous release with little synchronous component. The opposite was also true in that a small proportion of cells showed mostly synchronous release with little or no asynchro- 

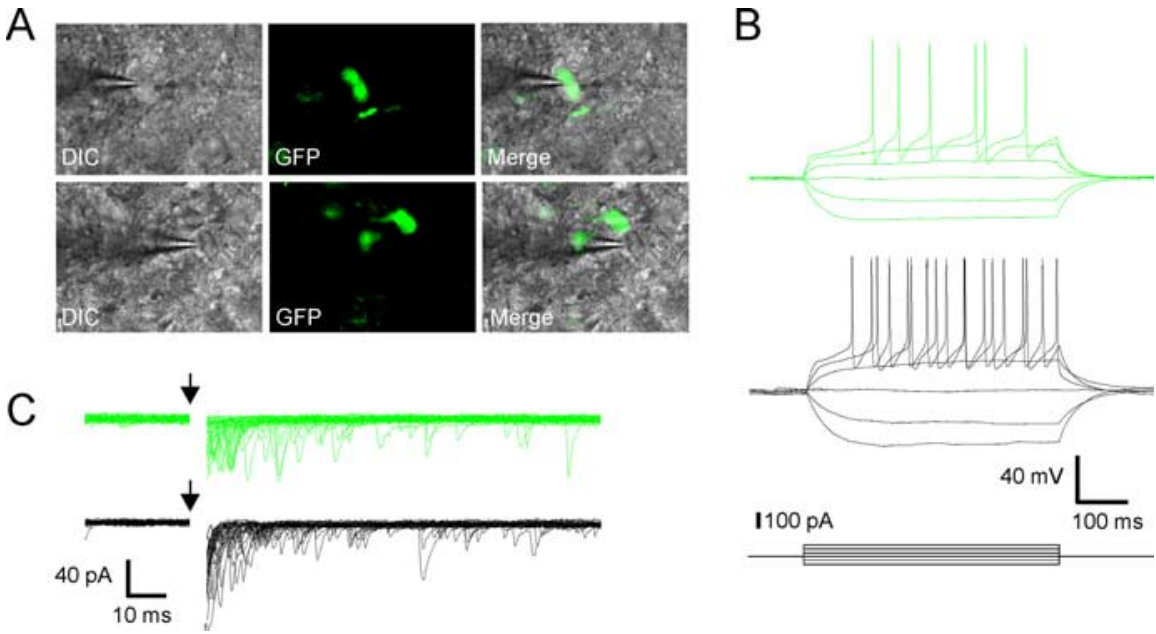

Figure 3. Asynchronous release does not depend on the phenotype of the postsynaptic cell. $A$, Whole-cell recordings were obtained from either GFP-positive (VP) or -negative (OT) neurons. B, GFP-positive and -negative cells had similar input resistances and responses to depolarizing current steps. $\boldsymbol{C}$, Representative traces show no difference in the amount of asynchronous release between the two cell types.

nous release. These cases accounted for $<10 \%$ of the total number of evoked responses recorded. Because transmitter release at inhibitory GABA synapses on MNCs can be regulated by the postsynaptic neuron (Oliet et al., 2007), we conducted experiments to determine whether the differences in release at glutamate synapses may also be a function of the target neuron. Here, we used a transgenic rat model in which eGFP is expressed exclusively by neurons producing VP (Ueta et al., 2005) to positively identify cells before recording (Fig. 3A). eGFP-positive cells (VP neurons) had a similar input resistance to eGFP negative cells (OT neurons; GFP +, $681 \pm 39 \mathrm{M} \Omega$; GFP-, $762 \pm 80 \mathrm{M} \Omega ; p>$ 0.05 ) (Fig. $3 B$ ). In response to synaptic stimulation, asynchronous release accounted for $0.49 \pm 0.03$ of the total synaptic charge in VP neurons $(n=12)$, and $0.50 \pm 0.04$ in non-VP neurons $(n=9 ; p>0.05)$ (Fig. $3 C)$. This indicates that the postsynaptic cell phenotype does not determine the degree of asynchronous glutamate release in MNCs.

\section{Asynchronous release is calcium dependent}

Asynchronous release of neurotransmitter at several other synapses has been postulated to result either from prolonged residual presynaptic calcium or a larger diffusion distance between the site of $\mathrm{Ca}^{2+}$ influx and the site of release (Rahamimoff and Yaari, 1973; Atluri and Regehr, 1998; Lu and Trussell, 2000; Wadel et al., 2007). To determine whether either of these mechanisms is responsible for the asynchronous release observed here, we bath applied the membrane permeant, slow $\mathrm{Ca}^{2+}$ chelator EGTA-AM. At low concentrations ( $25 \mu \mathrm{M}, 15 \mathrm{~min} ; n=5)$, EGTA-AM reduced the number of delayed release events $(p<0.05$ two way ANOVA at 5, 10, and $15 \mathrm{~ms}$ ) (Fig. $4 A, B$ ) and also reduced the asynchronous charge transfer (control, $0.270 \pm 0.045 \mathrm{pC}$; EGTA$\mathrm{AM}, 0.108 \pm 0.036 \mathrm{pC} ; n=5 ; p<0.01)$. At this concentration, there was no significant effect on the synchronous charge transfer (control, $0.315 \pm 0.057 \mathrm{pC}$; EGTA-AM, $0.234 \pm 0.044 \mathrm{pC} ; n=5$; $p>0.05)$. This resulted in a change in the fraction of asynchronous release/total charge from $0.47 \pm 0.04$ in control to $0.29 \pm$ 0.03 after EGTA-AM $(n=5)$. As expected, at higher concentrations $(50-100 \mu \mathrm{M})$, EGTA-AM reduced the asynchronous component more effectively, and in some cells reduced the initial synchronous component (Fig. $4 C)$ ( $n=6$; peak amplitude, con- trol, $250 \pm 108 \mathrm{pA} ; 100 \mu \mathrm{M}$ EGTA-AM, $106 \pm 48 \mathrm{pA} ; p<0.05)$. The selective reduction of delayed release by low concentrations of EGTA-AM also provides additional evidence against the idea that delayed release results from activation of polysynaptic circuits. To rule out the possibility that the loss of the asynchronous component may reflect a run-down phenomenon, we obtained recordings from the same cell after a 30 min interval. We found no change in the frequency of the asynchronous release events between this time period and control (Fig. $4 D)(p>$ $0.05 ; n=4)$.

\section{Postsynaptic buffering of calcium does not inhibit asynchronous release} Although there are several anecdotal reports that the effects of AM compounds are limited to presynaptic terminals and glial cells, we explicitly tested whether the effects of EGTA-AM may be partly the result of postsynaptic calcium buffering. With 10 mM EGTA in the whole-cell recording pipette, we found no rundown of asynchronous release and no difference in the amount of asynchronous release compared with control cells $(n=4 ; p>0.05)$ (data not shown). It is possible, however, that because of the time required to find a stimulation site and obtain control recordings, that the pipette solution containing EGTA had already dialyzed the cell and reduced asynchronous release. To exclude this possibility, we first patched a cell with normal internal solution and recorded evoked asynchronous currents. We then quickly retracted the pipette, re-patched the same cell with a pipette containing $10 \mathrm{mM}$ EGTA, and recorded currents evoked from the same stimulation site (Fig. 5) $(n=6)$. No difference in asynchronous release was found between the two different electrode solutions $(p>0.05)$. Our observations indicate that asynchronous release in response to a single action potential results from the sustained elevation of intraterminal $\mathrm{Ca}^{2+}$ and buffering postsynaptic $\mathrm{Ca}^{2+}$ has no effect on asynchronous release.

\section{Physiological trains of stimuli facilitate asynchronous release and prolonged spiking}

Most central neurons, including MNCs, not only receive inputs at low frequencies, but also in bursts (Washburn et al., 2000). Therefore, to determine the impact of delayed release during these bursts, we stimulated glutamatergic synapses using brief trains (four pulses) of stimuli in both voltage $(n=6)$ and current clamp $(n=8)$. In voltage clamp, short bursts of 20 or $50 \mathrm{~Hz}$ stimuli resulted in pronounced asynchronous release during and after the train $(20 \mathrm{~Hz}, 2.53 \pm 0.44 \mathrm{pC} ; 50 \mathrm{~Hz}, 2.79 \pm 0.47 \mathrm{pC} ; p>$ 0.05 ) (Fig. 6). The asynchronous release in response to $50 \mathrm{~Hz}$ stimulation was $\sim 2.5$ times the predicted charge from the simple sum of the asynchronous component of four single events $(1.09 \pm 0.17 \mathrm{pC}$, at $0.2 \mathrm{~Hz})$. At a lower stimulation frequency $(5$ $\mathrm{Hz}$ ), asynchronous release was also evident, but less pronounced than that observed at the higher frequencies $(1.97 \pm 0.37 \mathrm{pC}, p<$ 0.05 vs 20 or $50 \mathrm{~Hz}$ ).

To confirm that the asynchronous release induced by short trains had the same characteristics as that seen after single stimuli, we applied a low concentration of EGTA-AM. As with single stimuli, EGTA-AM $(25 \mu \mathrm{M})$ reduced the amount of burst stimu- 
lation induced asynchronous release by 51.3 and $54.1 \%$ for 20 and $50 \mathrm{~Hz}$, respectively $(20 \mathrm{~Hz}, 1.28 \pm 0.21 \mathrm{pC} ; 50 \mathrm{~Hz}$, $1.39 \pm 0.20$, control vs EGTA-AM; $p<$ $0.05 ; n=5$ ) (Fig. 6). The amount of asynchronous release in control or after EGTA-AM was not significantly different between the 20 and $50 \mathrm{~Hz}$ trains $(p>$ 0.05). Synchronous release during the train was not significantly different in the presence of EGTA-AM ( $p>0.05)$ (Fig. 6C,D).

Finally, we investigated the impact of asynchronous release during physiologically relevant stimulus trains on spike activity in MNCs. In current clamp, activation of afferents at both 20 and $50 \mathrm{~Hz}$ reliably elicited spiking in the $20 \mathrm{~ms}$ time window after each stimulus (synchronous spikes). In addition to this time-locked activity, we also observed robust spiking (asynchronous spikes) that persisted even after the termination of the synaptic stimulation (Fig. $7 A, B)(n=8)$. At these stimulation frequencies, we observed no difference in the number of synchronous spikes $(20 \mathrm{~Hz}$ stimulation, $86.5 \pm 11.1$ spikes; $50 \mathrm{~Hz}$ stimulation, $91.7 \pm 9.4$ spikes; $p>0.05$ ) (Fig. 7E). In contrast, $20 \mathrm{~Hz}$ stimulation was less effective at eliciting asynchronous spikes compared with $50 \mathrm{~Hz}$ stimulation (20 Hz stimulation, $39.9 \pm 6.3$ spikes; $50 \mathrm{~Hz}$ stimulation, $73.6 \pm$ $18.9 ; n=8 ; p<0.05$ ) (Fig. $7 F$ ). Finally, we conducted experiments to assess the contributions of asynchronous glutamate release to stimulus-induced spiking. Reducing asynchronous release with EGTA-AM had no effect on the number of synchronous spikes elicited during the stimulus trains $(20 \mathrm{~Hz}$ stimulation, $73.0 \pm 11.8 ; 50 \mathrm{~Hz}$ stimulation, $74.0 \pm 8.6 ; n=8$; $p>0.05$ comparing control and EGTA-AM) (Fig. $7 C-F)$. The reduction of asynchronous glutamate release, however, was accompanied by a reduction in the number of asynchronous spikes observed after both 20 and $50 \mathrm{~Hz}$ stimulation $(20 \mathrm{~Hz}$ stimulation, $6.3 \pm 2.0$ spikes; $50 \mathrm{~Hz}$ stimulation, $11.1 \pm 2.0$ spikes; $p<0.05$, comparing control and EGTA-AM; $n=8$ ) (Fig. $7 C-F$ ). These findings suggest that asynchronous glutamate release can have an amplifying effect on cellular excitability after short, physiologically relevant trains of stimuli.

\section{Discussion}

The results described here provide the first demonstration that glutamatergic afferents in PVN use both synchronous and asynchronous modes of neurotransmitter release. The asynchronous component was particularly sensitive to $\mathrm{Ca}^{2+}$ buffering indicating that it likely occurs in response to residual $\mathrm{Ca}^{2+}$ in the terminal and may result from the release of vesicles located some distance from the mouth of the $\mathrm{Ca}^{2+}$ channel (Fedchyshyn and Wang, 2005; Hefft and Jonas, 2005; Wadel et al., 2007). Repetitive activation of afferents further enhanced asynchronous release in a supralinear manner. Finally, our findings demonstrate that one important functional consequence of this asynchronous release is to increase the duration for which postsynaptic neurons are able to elicit spikes in response to activation of the presynaptic terminal.

To date, asynchronous release has been observed in both the PNS (David and Barrett, 2003) and CNS (Atluri and Regehr, 1998; Lu and Trussell, 2000; Otsu et al., 2004; Hefft and Jonas,
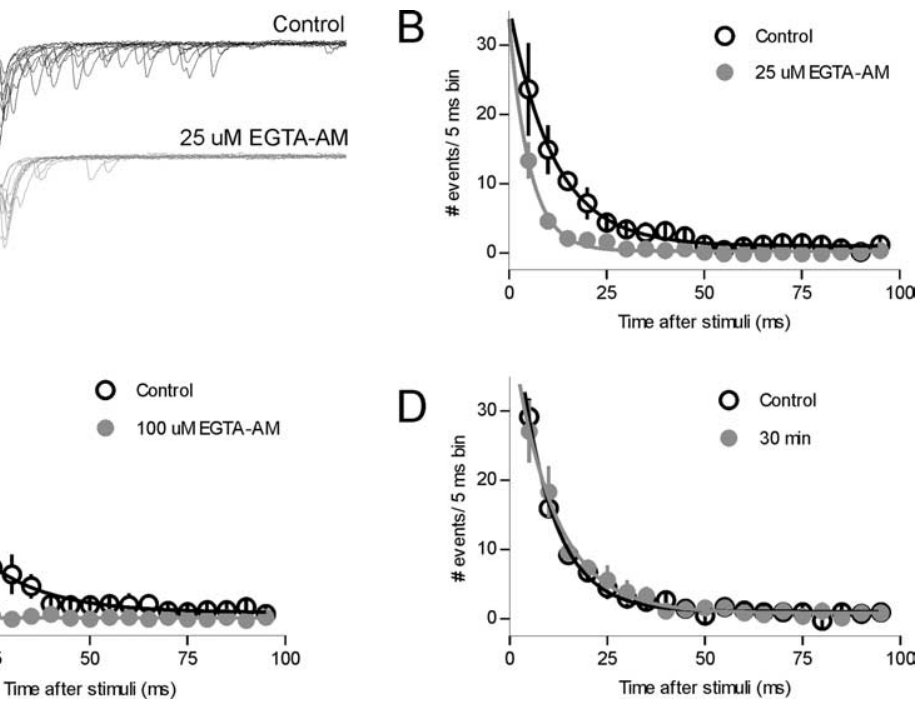

Asynchronous release is calcium dependent. $\boldsymbol{A}$, Voltage-clamp traces from a single neuron show the effect of the asynchronous release over the $30 \mathrm{~min}$.
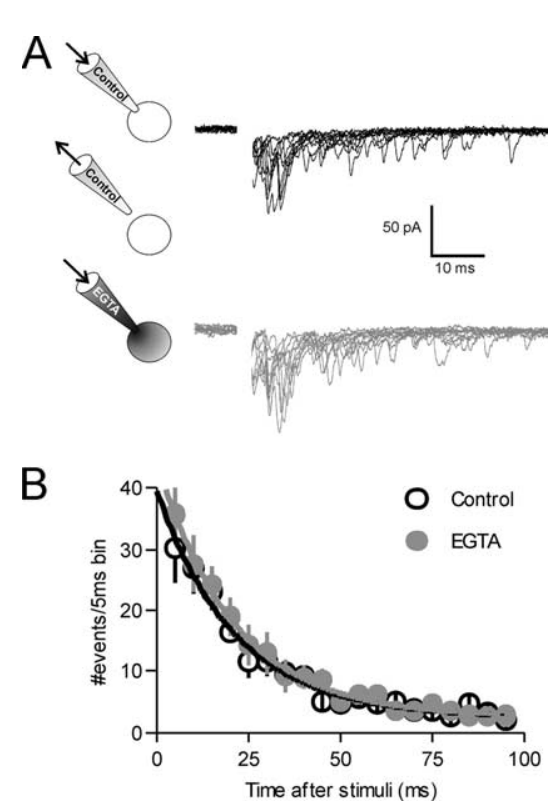

Figure 5. Buffering postsynaptic $\mathrm{Ca}^{2+}$ does not inhibit asynchronous release. $\boldsymbol{A}$, Whole-cell recordings were first made with normal internal pipette solution. Evoked currents were recorded for a control period and the pipette was quickly withdrawn from the cell. The same cell was then repatched with a pipette containing $10 \mathrm{~mm}$ EGTA $(n=6)$. Evoked currents were recorded for up to $30 \mathrm{~min}$ with the new internal solution. $\boldsymbol{B}$, There was no difference in evoked currents recorded with either normal (black traces) or EGTA containing pipette solution (gray traces, $p>0.05$ ). Evoked currents used for analysis in $\boldsymbol{B}$ were obtained $16.7 \pm 1.7 \mathrm{~min}$ after repatching the cell.

2005; Hjelmstad, 2005). Although most of the studies have used mammalian preparations, this form of transmission is also observed at the frog and crayfish neuromuscular junction (Rahamimoff and Yaari, 1973; Ravin et al., 1997). Because of the ubiquitous nature of this form of transmission, it likely has an important role in information processing distinct from synchronous release. It has been proposed that asynchronous release may smooth out postsynaptic responses during high-frequency trains 


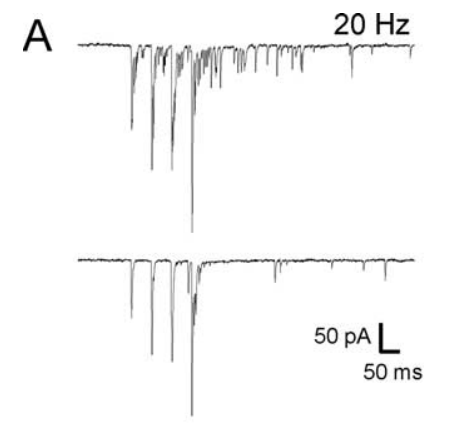

C

B

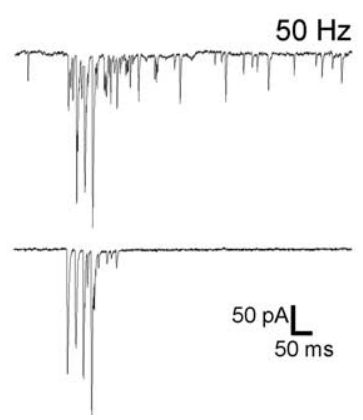

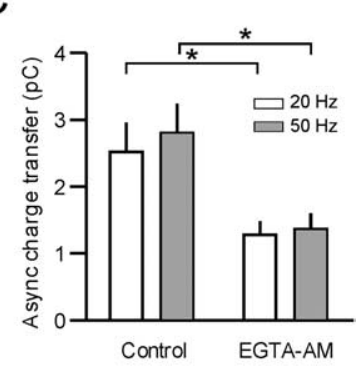

$\mathrm{D}$

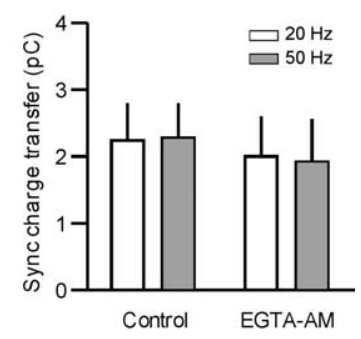

Figure 6. Asynchronous release accumulates during repetitive afferent activity. $A, B$, Representative voltage-clamp traces during short (four pulse) trains at $20(\boldsymbol{A})$ and $50 \mathrm{~Hz}(\boldsymbol{B})$. Top traces are control and bottom traces are after application of $25 \mu \mathrm{m}$ EGTA-AM. Stimulation artifacts have been removed for clarity. $C$, Quantification of these data show that asynchronous charge transfer elicited by 20 and $50 \mathrm{~Hz}$ trains in control was $2.53 \pm 0.44 \mathrm{pC}$ and $2.79 \pm 0.47$ $\mathrm{pC}$, respectively. After application of $25 \mu \mathrm{M}$ EGTA-AM, asynchronous release was $1.28 \pm 0.21$ $p C$ and $1.39 \pm 0.20 p C$ for the 20 and $50 \mathrm{~Hz}$ trains respectively ( $\left.{ }^{*} p<0.05 ; n=5\right)$. D. The synchronous component of release during the trains was not inhibited after EGTA-AM $(20 \mathrm{~Hz}$ control, $2.23 \pm 0.58 \mathrm{pC} ; 20 \mathrm{~Hz}$ EGTA-AM, $2.01 \pm 0.60 \mathrm{pC} ; p>0.05 ; 50 \mathrm{~Hz}$ control, $2.28 \pm 0.52$ pC; EGTA-AM, $1.94 \pm 0.61 \mathrm{pC} ; p>0.05 ; n=5)$.

(Lu and Trussell, 2000) or act as a memory trace by maintaining presynaptic and postsynaptic activity after high-frequency afferent activity (Atluri and Regehr, 1998; Hjelmstad, 2005). Alternatively, it has been suggested that synchronous and asynchronous transmission may function to separately control the gain and offset of neuronal networks (Hefft and Jonas, 2005). In this study, delayed, asynchronous release of glutamate from presynaptic terminals is integrated by the postsynaptic cell to generate large, prolonged EPSPs. In the hypothalamo-neurohypophyseal system, this may be an ideal way to fully take advantage of slow depolarizations that result from the activation of postsynaptic conductances in response to local changes in osmolarity (Oliet and Bourque, 1993) or release of neuropeptides (Ferguson et al., 2001). By providing a long time window during which synaptic inputs are active, asynchronous release provides a way to maximize postsynaptic excitability when MNCs are closer to spike threshold.

There are few examples in the vertebrate CNS where single stimuli evoke such prodigious delayed, asynchronous neurotransmitter release as that described here in the PVN. The parallel fiber to stellate cell synapse also displays considerable asynchronous release (Atluri and Regehr, 1998); however, because it is associated with a relatively large synchronous event, the proportional contribution of asynchronous release to the total synaptic charge is relatively small. Although the vast majority of EPSCs recorded in MNCs displayed synchronous followed by asynchronous release, in some trials we did observe either exclusive asynchronous release with little synchronous component or synchronous release with little or no asynchronous component $(<10 \%$ of
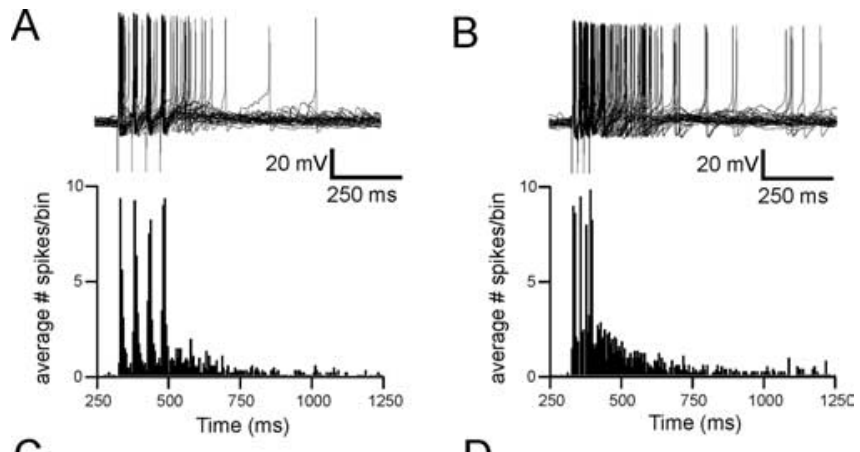

C
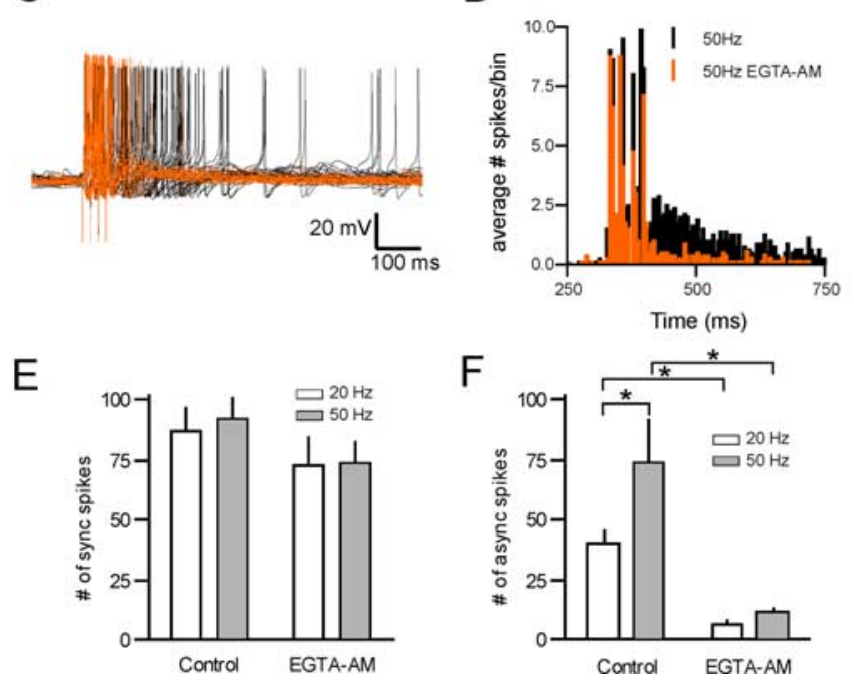

Figure 7. Asynchronous release promotes prolonged spiking. $A, B$, Representative currentclamp traces during short (four pulse) trains at $20 \mathrm{~Hz}(\boldsymbol{A}$, top) and $50 \mathrm{~Hz}$ ( $\boldsymbol{B}$, top, 30 overlaid traces in each condition). Average spike histograms from eight cells are shown under each trace. C, Current-clamp traces at $50 \mathrm{~Hz}$ before (black) and after (orange) $25 \mu \mathrm{m}$ EGTA-AM. D, Histogram plotting the average number of spikes $/ 5 \mathrm{~ms}$ bin over time for the $50 \mathrm{~Hz}$ train, both in control (black) and after EGTA-AM (orange). The data represent the average from eight cells (30 trials per cell). $\boldsymbol{E}$, The number of synchronous spikes evoked during the stimulation train both in control and after EGTA-AM (control vs EGTA, ANOVA, $p>0.05 ; n=8$ ). $\boldsymbol{F}$, The number of spikes evoked in the $500 \mathrm{~ms}$ after the end of the stimulation train in control and after application of 25 $\mu$ M EGTA-AM (control vs EGTA-AM, ANOVA, ${ }^{*} p<0.05 ; n=8$ ).

cells). These discrepancies may reflect the possibility that afferent axons originating from different nuclei are associated with functionally different presynaptic terminals.

Although we have not examined the precise mechanisms underlying asynchronous release in PVN explicitly, our demonstration that asynchronous release was susceptible to the slow calcium buffer EGTA-AM is consistent with several mechanisms that have been proposed in other systems, including a larger distance between the calcium source and sensor (Meinrenken et al., 2002; Fedchyshyn and Wang, 2005; Hefft and Jonas, 2005), a prolonged presynaptic $\mathrm{Ca}^{2+}$ transient (Atluri and Regehr, 1996), and a different $\mathrm{Ca}^{2+}$ sensor for asynchronous compared with synchronous release (Geppert et al., 1994; Nishiki and Augustine, 2004; Hui et al., 2005). In the calyx of Held, the profile of transmitter release is developmentally regulated (Fedchyshyn and Wang, 2005). Here, we find that asynchronous release was present in both young and older animals suggesting that it is a conserved form of neurotransmission in the PVN and is not sensitive to developmental regulation.

Asynchronous release was potentiated during short trains of stimuli resulting in a pronounced inward current after the end of the train. The asynchronous release during and after the $50 \mathrm{~Hz}$ 
burst was $\sim 2.5$ times the predicted charge from the simple sum of the asynchronous component of four single events. This observation is in line with the proposed reliance of asynchronous release on residual $\mathrm{Ca}^{2+}$. At glutamate synapses on MNCs in the supraoptic nucleus, short-term potentiation of glutamate release has been described previously in response to high-frequency tetanization of afferents (Kombian et al., 2000). It is not clear whether this is a unique phenomenon or whether it reflects a buildup of successive asynchronous release events. Our data, using multiple stimuli, indicate that the robust increase in EPSC frequency that follows tetanization of afferents may result from the summation of asynchronous release events. This finding, however, does not explicitly rule out the contributions of other processes that may also be recruited during prolonged episodes of high-frequency activation. In fact, at some synapses, asynchronous release in response to a single action potential is not a prerequisite for the subsequent release of multiple quanta in response to high-frequency stimulation ( $\mathrm{Lu}$ and Trussell, 2000; Otsu et al., 2004).

\section{Functional role of asynchronous release}

Finally, our findings reveal that asynchronous release may have important functional consequences for the recruitment of MNCs during specific patterns of afferent activity. Because neurons that provide excitatory input to MNCs exhibit bursts of activity (Washburn et al., 2000), our observations that a brief afferent discharge can increase postsynaptic activity for a prolonged period of time indicates that asynchronous release is an important component of signal transfer at these synapses. Previous work showing that asynchronous release in recurrently connected networks of hippocampal neurons is necessary for bursting (Lau and Bi, 2005; Wyart et al., 2005) supports the idea that this form of transmission may be functionally important for translating synaptic signals into specific patterns of neuronal activity. Second, the prolonged depolarization (and spiking) mediated by asynchronous release may facilitate the opening of postsynaptic NMDA receptors and voltage-gated calcium channels. The resulting calcium influx should promote both the dendritic release of peptides from MNCs (Ludwig and Pittman, 2003) and the induction of synaptic plasticity (Panatier et al., 2006).

Most neurons in the CNS require fast, precise intercellular signaling to efficiently transfer and process information. In these circuits, where timing of inputs is at a premium, asynchronous release may be counterproductive. For some neurons in the CNS, such as MNCs, temporal resolution may not be critical. Instead, these cells are specialized to integrate inputs from several nuclei into a final "output" signal. Asynchronous glutamate release may provide a mechanism to amplify presynaptic activity and promote prolonged spiking in response to temporally dispersed afferent inputs and may be a particularly effective way to ensure a faithful neuronal response during intense physiological demand.

\section{References}

Armstrong WE, Smith BN, Tian M (1994) Electrophysiological characteristics of immunochemically identified rat oxytocin and vasopressin neurones in vitro. J Physiol (Lond) 475:115-128.

Atluri PP, Regehr WG (1996) Determinants of the time course of facilitation at the granule cell to Purkinje cell synapse. J Neurosci 16:5661-5671.

Atluri PP, Regehr WG (1998) Delayed release of neurotransmitter from cerebellar granule cells. J Neurosci 18:8214-8227.

Barrett EF, Stevens CF (1972) The kinetics of transmitter release at the frog neuromuscular junction. J Physiol (Lond) 227:691-708.

Boudaba C, Schrader LA, Tasker JG (1997) Physiological evidence for local excitatory synaptic circuits in the rat hypothalamus. J Neurophysiol 77:3396-3400.
Bourque CW, Renaud LP (1991) Membrane properties of rat magnocellular neuroendocrine cells in vivo. Brain Res 540:349-352.

Bourque CW, Randle JC, Renaud LP (1985) Calcium-dependent potassium conductance in rat supraoptic nucleus neurosecretory neurons. J Neurophysiol 54:1375-1382.

Brown CH, Bull PM, Bourque CW (2004) Phasic bursts in rat magnocellular neurosecretory cells are not intrinsically regenerative in vivo. Eur J Neurosci 19:2977-2983.

Brussaard AB, Kits KS, de Vlieger TA (1996) Postsynaptic mechanism of depression of GABAergic synapses by oxytocin in the supraoptic nucleus of immature rat. J Physiol (Lond) 497:495-507.

Cathala L, Brickley S, Cull-Candy S, Farrant M (2003) Maturation of EPSCs and intrinsic membrane properties enhances precision at a cerebellar synapse. J Neurosci 23:6074-6085.

Cohen IS, Van der Kloot W (1986) Facilitation and delayed release at single frog neuromuscular junctions. J Neurosci 6:2366-2370.

David G, Barrett EF (2003) Mitochondrial $\mathrm{Ca}^{2+}$ uptake prevents desynchronization of quantal release and minimizes depletion during repetitive stimulation of mouse motor nerve terminals. J Physiol (Lond) 548: 425-438.

Fedchyshyn MJ, Wang LY (2005) Developmental transformation of the release modality at the calyx of Held synapse. J Neurosci 25:4131-4140.

Ferguson AV, Day TA, Renaud LP (1984) Subfornical organ efferents influence the excitability of neurohypophyseal and tuberoinfundibular paraventricular nucleus neurons in the rat. Neuroendocrinology 39:423-428.

Ferguson AV, Washburn DL, Latchford KJ (2001) Hormonal and neurotransmitter roles for angiotensin in the regulation of central autonomic function. Exp Biol Med (Maywood) 226:85-96.

Fisher TE, Voisin DL, Bourque CW (1998) Density of transient $\mathrm{K}^{+}$current influences excitability in acutely isolated vasopressin and oxytocin neurones of rat hypothalamus. J Physiol (Lond) 511:423-432.

Geppert M, Goda Y, Hammer RE, Li C, Rosahl TW, Stevens CF, Sudhof TC (1994) Synaptotagmin I: a major $\mathrm{Ca}^{2+}$ sensor for transmitter release at a central synapse. Cell 79:717-727.

Hefft S, Jonas P (2005) Asynchronous GABA release generates long-lasting inhibition at a hippocampal interneuron-principal neuron synapse. Nat Neurosci 8:1319-1328.

Hirasawa M, Mouginot D, Kozoriz MG, Kombian SB, Pittman QJ (2003) Vasopressin differentially modulates non-NMDA receptors in vasopres$\sin$ and oxytocin neurons in the supraoptic nucleus. J Neurosci 23:4270-4277.

Hirasawa M, Schwab Y, Natah S, Hillard CJ, Mackie K, Sharkey KA, Pittman QJ (2004) Dendritically released transmitters cooperate via autocrine and retrograde actions to inhibit afferent excitation in rat brain. J Physiol (Lond) 559:611-624.

Hjelmstad GO (2005) Interactions between asynchronous release and short-term plasticity in the nucleus accumbens slice. J Neurophysiol 95:2020-2023.

Hui E, Bai J, Wang P, Sugimori M, Llinas RR, Chapman ER (2005) Three distinct kinetic groupings of the synaptotagmin family: candidate sensors for rapid and delayed exocytosis. Proc Natl Acad Sci USA 102:5210-5214.

Iremonger KJ, Bains JS (2006) Asynchronous glutamate release prolongs post-synaptic excitation in central neurons. Soc Neurosci Abstr 32:794.3.

Kombian SB, Mouginot D, Pittman QJ (1997) Dendritically released peptides act as retrograde modulators of afferent excitation in the supraoptic nucleus in vitro. Neuron 19:903-912.

Kombian SB, Hirasawa M, Mouginot D, Chen X, Pittman QJ (2000) Shortterm potentiation of miniature excitatory synaptic currents causes excitation of supraoptic neurons. J Neurophysiol 83:2542-2553.

Lau PM, Bi GQ (2005) Synaptic mechanisms of persistent reverberatory activity in neuronal networks. Proc Natl Acad Sci USA 102:10333-10338.

Li Z, Ferguson AV (1993) Subfornical organ efferents to paraventricular nucleus utilize angiotensin as a neurotransmitter. Am J Physiol 265:R302-R309.

Lu T, Trussell LO (2000) Inhibitory transmission mediated by asynchronous transmitter release. Neuron 26:683-694.

Ludwig M, Pittman QJ (2003) Talking back: dendritic neurotransmitter release. Trends Neurosci 26:255-261.

Ludwig M, Sabatier N, Bull PM, Landgraf R, Dayanithi G, Leng G (2002) Intracellular calcium stores regulate activity-dependent neuropeptide release from dendrites. Nature 418:85-89.

Luther JA, Tasker JG (2000) Voltage-gated currents distinguish parvocellu- 
lar from magnocellular neurones in the rat hypothalamic paraventricular nucleus. J Physiol (Lond) 523:193-209.

Meinrenken CJ, Borst JG, Sakmann B (2002) Calcium secretion coupling at calyx of Held governed by nonuniform channel-vesicle topography. J Neurosci 22:1648-1667.

Moos F, Poulain DA, Rodriguez F, Guerne Y, Vincent JD, Richard P (1989) Release of oxytocin within the supraoptic nucleus during the milk ejection reflex in rats. Exp Brain Res 76:593-602.

Nishiki T, Augustine GJ (2004) Synaptotagmin I synchronizes transmitter release in mouse hippocampal neurons. J Neurosci 24:6127-6132.

Nissen R, Hu B, Renaud LP (1995) Regulation of spontaneous phasic firing of rat supraoptic vasopressin neurones in vivo by glutamate receptors. J Physiol (Lond) 484:415-424.

Oliet SH, Bourque CW (1993) Mechanosensitive channels transduce osmosensitivity in supraoptic neurons. Nature 364:341-343.

Oliet SH, Baimoukhametova DV, Piet R, Bains JS (2007) Retrograde regulation of GABA transmission by the tonic release of oxytocin and endocannabinoids governs postsynaptic firing. J Neurosci 27:1325-1333.

Otsu Y, Shahrezaei V, Li B, Raymond LA, Delaney KR, Murphy TH (2004) Competition between phasic and asynchronous release for recovered synaptic vesicles at developing hippocampal autaptic synapses. J Neurosci 24:420-433.

Panatier A, Gentles SJ, Bourque CW, Oliet SH (2006) Activity-dependent synaptic plasticity in the supraoptic nucleus of the rat hypothalamus. J Physiol (Lond) 573:711-721.

Pow DV, Morris JF (1989) Dendrites of hypothalamic magnocellular neurons release neurohypophysial peptides by exocytosis. Neuroscience 32:435-439.

Rahamimoff R, Yaari Y (1973) Delayed release of transmitter at the frog neuromuscular junction. J Physiol (Lond) 228:241-257.

Ravin R, Spira ME, Parnas H, Parnas I (1997) Simultaneous measurement of intracellular $\mathrm{Ca}^{2+}$ and asynchronous transmitter release from the same crayfish bouton. J Physiol (Lond) 501:251-262.

Roper P, Callaway J, Armstrong W (2004) Burst initiation and termination in phasic vasopressin cells of the rat supraoptic nucleus: a combined mathematical, electrical, and calcium fluorescence study. J Neurosci 24:4818-4831.

Sabatier N, Caquineau C, Dayanithi G, Bull P, Douglas AJ, Guan XM, Jiang M, Van der PL, Leng G (2003) Alpha-melanocyte-stimulating hormone stimulates oxytocin release from the dendrites of hypothalamic neurons while inhibiting oxytocin release from their terminals in the neurohypophysis. J Neurosci 23:10351-10358.

Ueta Y, Fujihara H, Serino R, Dayanithi G, Ozawa H, Matsuda K, Kawata M, Yamada J, Ueno S, Fukuda A, Murphy D (2005) Transgenic expression of enhanced green fluorescent protein enables direct visualization for physiological studies of vasopressin neurons and isolated nerve terminals of the rat. Endocrinology 146:406-413.

Wadel K, Neher E, Sakaba T (2007) The coupling between synaptic vesicles and $\mathrm{Ca}(2+)$ channels determines fast neurotransmitter release. Neuron 53:563-575.

Wang YF, Hatton GI (2007) Dominant role of $\beta \gamma$ subunits of G-proteins in oxytocin-evoked burst firing. J Neurosci 27:1902-1912.

Washburn DL, Anderson JW, Ferguson AV (2000) A subthreshold persistent sodium current mediates bursting in rat subfornical organ neurones. J Physiol (Lond) 529:359-371.

Watson SJ, Akil H, Fischli W, Goldstein A, Zimmerman E, Nilaver G, van wimersma Griedanus TB (1982) Dynorphin and vasopressin: common localization in magnocellular neurons. Science 216:85-87.

Wyart C, Cocco S, Bourdieu L, Leger JF, Herr C, Chatenay D (2005) Dynamics of excitatory synaptic components in sustained firing at low rates. J Neurophysiol 93:3370-3380. 